\title{
Reabilitação oral com prótese provisória imediata: relato de caso
}

\author{
Oral rehabilitation with immediate provisional prosthesis: case report
}

GONÇALVES, Weverson da Costa'; FERNANDES, Samuel Lucas ${ }^{2}$, SANTOS, Diogo de Moura ${ }^{3}$; ALVES, Scatlett Dalet'; CARRIJO, Mônica Oliveira ${ }^{4}$; GONÇALVES JÚNIOR, Ubiratan'; ${ }^{5}$ SANTANA, Tawan Manze ${ }^{6}$

1. Graduando em Odontologia, Faculdade Morgana Potrich, Mineiros, GO, Brasil.

2. Mestre em Ciências Odontológicas Aplicadas. Professor da Universidade Brasil, Fernandópolis, SP, Brasil.

3. Graduando em Odontologia, Universidade Brasil, Fernandópolis, SP, Brasil.

4. Mestre em Implantodontia, Centro Universitário da Fundação Educacional de Barretos, Barretos, SP, Brasil.

5. Mestre em Clínica Odontológica. Professor do Centro Universitário Unicerrado, Goiatuba, GO, Brasil.

6. Especialista em Cirurgia e Traumatologia Buco Maxilo Facial.

Endereço para correspondência:

Samuel Lucas Fernandes

Faculdade de Odontologia de Bauru - USP

Disciplina de Endodontia

Alameda Doutor Octávio Pinheiro Brisolla, 9-75

17012-901 - Bauru - São Paulo - Brasil

E-mail: samuel.lukas.usp@gmail.com

Recebido: 24.07 .2017

Aceito: 12.11.2017

\section{RESUMO}

A prótese instalada imediatamente após a extração dos dentes naturais proporciona ao paciente estética e função, evita a perca de dimensão vertical de oclusão e restabelece a função mastigatória, prevenindo futuras disfunções na articulação temporomandibular, possibilitando a reinserção do paciente no convívio social. Nesse contexto, o objetivo desse trabalho foi relatar a confecção de uma prótese parcial removível imediata no mesmo dia que a paciente iria se submeter a extrações dentárias múltiplas em região estética, evitando assim transtornos sociais e psicológicos pela falta dos dentes. O resultado foi considerado extraordinário devolvendo o bem-estar do paciente.

Palavras-chave: Estética dentária. Prótese dentária. Dentística operatória.

\begin{abstract}
The prosthesis installed immediately after extraction of natural teeth provides the patient with esthetics and function, avoids the loss of vertical dimension of occlusion and reestablishes the masticatory function, preventing future dysfunctions in the temporomandibular joint, making possible the reintegration of the patient in social life. In this context, the objective this study was report the manufacture of an immediate removable partial denture on the same day that the patient would undergo multiple dental extractions in aesthetic region, thus avoiding social and psychological disorders due to privation of teeth. The result considered extraordinary restoring the patient's well-being.
\end{abstract}

Keywords: Esthetics, dental. Dental prosthesis. Dentistry, operative. 


\section{INTRODUÇÃO}

O comprometimento da saúde bucal dos pacientes pode afetar seu estado nutricional, físico e mental, e prejudica uma vida social atival, principalmente quando se perde dentes anteriores ${ }^{2}$. Apesar de uma ampla gama de opções de tratamento disponíveis, às vezes, é inevitável para salvar o dente natural ${ }^{2}$.

As próteses imediatas podem ser definidas como uma prótese parcial ou total confeccionadas para serem instaladas imediatamente após exodontias ${ }^{3}$. Esses tipos de prótese podem ser utilizados por razões estéticas, mastigatória, como suporte oclusal, por conveniência ou para a adaptação do paciente do estado dentado ao desdentado, até a instalação de uma prótese definitiva ${ }^{4}$.

A confecção de próteses imediatas envolve procedimentos prévios a exodontia e a instalação e ajustes logo após a cirurgia ${ }^{5-7}$. A prótese imediata propicia ao paciente a reabilitação estética e funcional imediata, levando-o a um melhor estado psicológico. Além disso, permite um melhor pós-operatório ${ }^{6-7}$, uma vez que protege 0 coagulo e a ferida cirúrgica, proporcionando a cicatrização nos limites da prótese e uma boa acomodação dos tecidos.

Por esses motivos é que a prótese imediata não deve ser encarada simplesmente como uma alternativa inevitável a uma Odontologia mais conservadora e sim um tipo de reabilitação que requer mais conhecimentos, habilidades e critérios de que a prótese temporária convencional, frequentemente apresentando um resultado desconcertante para o profissional. Portanto, para se obter um bom resultado do tratamento, minimizando o comprometimento da qualidade de vida do paciente com a perda dos dentes naturais, o cirurgião-dentista precisa compreender as consequências de se subestimar as dificuldades inerentes a esse tipo de tratamento.

O objetivo do presente trabalho foi relatar o planejamento cirúrgico-protético da reabilitação de uma paciente, por meio de prótese parcial imediata maxilar, bem como os resultados obtidos com essa modalidade de tratamento.

\section{RELATO DE CASO}

Paciente de 45 anos de idade, do gênero feminino, fumante, domiciliado em Mineiros, que compareceu à Clínica Escola de Odontologia da Faculdade Morgana Potrich (FAMP). Ao exame clínico observou-se ampla destruição coronária dos dentes superiores, elementos 11 , $12,13,14,15,21,22,23,24,25$. Foi apresentado um plano de tratamento a paciente a fim de resolver o problema causado pela extensa destruição coronária, sem condições funcionais e estética.

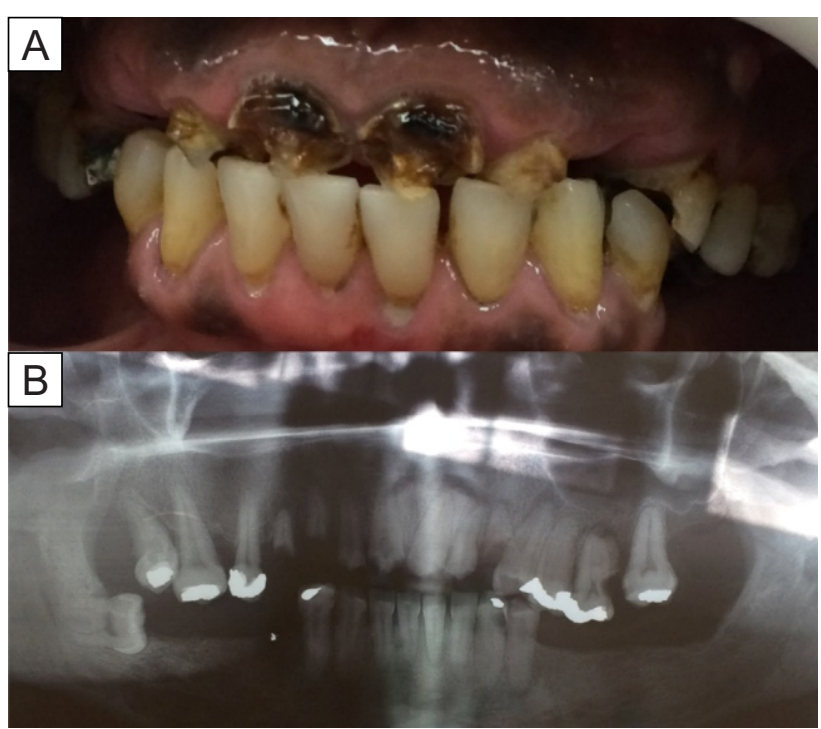

Figura 1 -Aspecto clinico (A) e radiográfico (B) inicial.

Após realizar a anamnese, exame clínico e exames radiográficos conclui-se que a melhor forma de reabilitar a paciente seria através de uma prótese total imediata. Realizouse um modelo de estudo no qual foram removidos os dentes que seriam extraídos antes e depois da colocação da prótese parcial removível. Para obtenção do modelo, foi utilizado elastômero para moldagem e vazado em gesso pedra. Em casos de necessidade de reabilitação imediata de elementos dentários, adequando-o às condições socioeconômicas do paciente, promovendo o restabelecimento estético e funcional.

Foi planejada a extração dos elementos dentários. No pré-operatório a paciente fez uso profilático de amoxicilina ( $1 \mathrm{~g})$, uma hora antes da extração. Antes do procedimento cirúrgico, a prótese e o guia cirúrgico foram imersos em clorexidina $2 \%$ para realizar desinfecção. Foi realizada a antissepsia no rosto da paciente com clorexidina $2 \%$. Inicialmente foi realizada a extração de todos os elementos dentários, e com auxílio do guia cirúrgico foram realizadas osteoplastia e gengivoplastia minimizando ajustes da prótese total imediata. Realizada a sutura e reembasamento da prótese com material macio (Densell Dentusoft Dentusoft Clear Dentusoft Bacter $\left.{ }^{\circledR}\right)$.

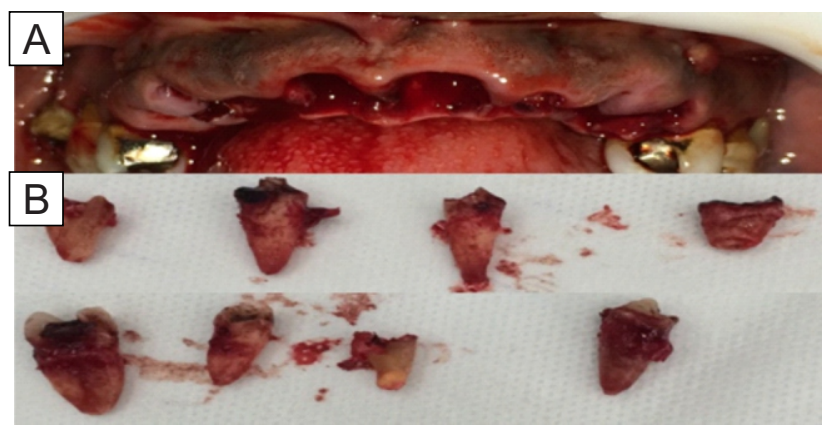

Figura 2 -Alvéolos após exodontia (A) e dentes extraídos (B). 
Finalizada a extração e instalação da prótese total imediata, instruiu-se o paciente a fazer continuidade dos medicamentos conforme o receituário (amoxicilina 500 $\mathrm{mg}$, nimesulida $100 \mathrm{mg}$, dipirona sódica $500 \mathrm{mg}$ ), e a maneira correta de higienizar (como é feita a higienização). Depois de uma semana, a mesma compareceu novamente a clínica para remoção dos pontos e realização dos ajustes necessários.

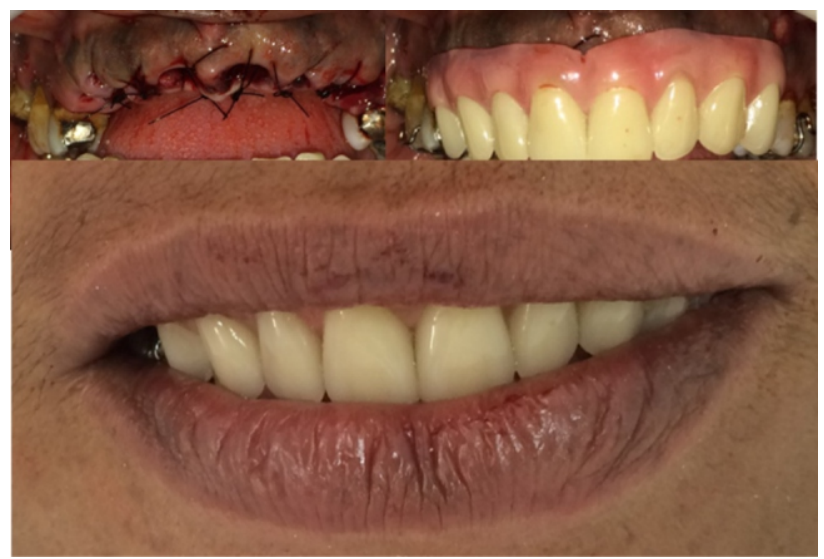

Figura 3 - Aspecto após a sutura, instalação e ajuste inicial da prótese.

Após uma semana do ato cirúrgico, através de novo exame clinico observou-se excelentes condições na cavidade oral. A paciente relatou satisfação com a estética, principalmente devido ao fato de não apresentar os dentes anteriores superiores, o que interferia em seu sorriso.

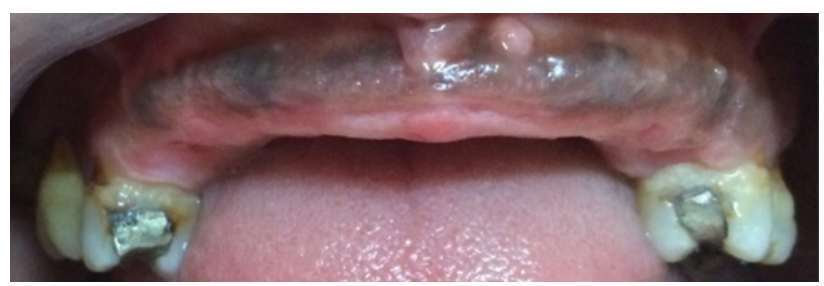

Figura 4 - Aspecto final, após a remoção da sutura.

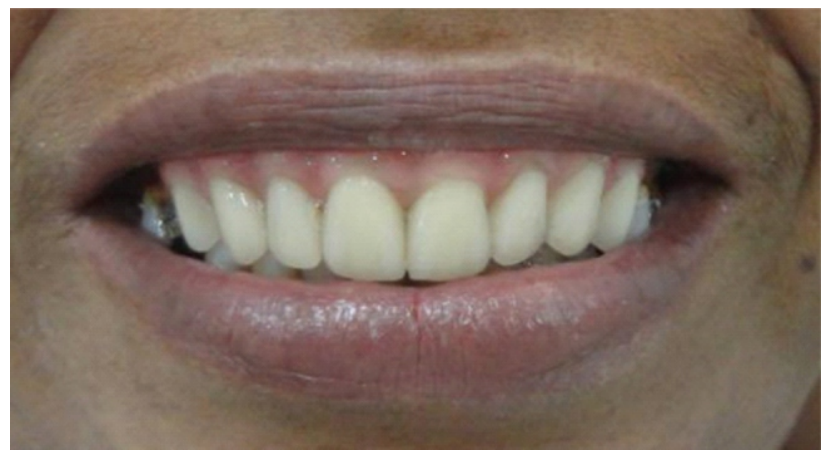

Figura 5 - Aspecto final do sorriso.

\section{DISCUSSÃO}

A cárie dentária afeta a qualidade de saúde bucal do indivíduo e gera inúmeros desconfortos uma vez que a sua evolução, leva a dor, perda de função e da estética, levando o paciente a uma perda de saúde sistêmica e transtornos psíquicos. A paciente do relato em questão relatava desconforto para a mastigação, além de estar incomodada com a estética dos seus dentes anteriores. Após o exame radiográfico foi dada a opção de tratamento da exodontia dos dentes comprometidos e colocação de prótese parcial imediata. A paciente aceitou prontamente o tratamento.

A confecção de próteses parciais imediatas envolve procedimentos de moldagens previas a cirurgia para se realizar uma cirurgia previa no modelo de estudo e confecção da prótese imediata. Após a confecção da prótese se faz as exodontias e a instalação da prótese com os devidos ajustes $^{5-7}$. Esse procedimento permite o reestabelecimento das funções mastigatórias, estética e fonética, e neste caso podemos observar que a prótese imediata cumpriu o seu papel, estabelecendo as funções esperadas.

Para a execução desse procedimento foi realizada uma moldagem inicial e os passos foram seguidos de forma adequada, propiciando a confecção de uma prótese que necessitou de mínimos ajustes logo na instalação. A cirurgia facilitou o processo de instalação, uma vez que foi realizada a remoção dos dentes e regularização do rebordo, removendo as espículas ósseas e com uma sutura eficiente.

O tratamento odontológico deverá alcançar, por meio da restauração dos dentes naturais e/ou da substituição dos dentes perdidos, uma função mastigatória aceitável8. Na segunda consulta a paciente já se mostrou extremamente satisfeita tanto com a estética quanto com a funcionalidade da prótese, sendo assim atendeu as expectativas do tratamento estabelecido. Na segunda sessão foi realizado um refinamento dos ajustes e um polimento da prótese. Após seis meses a paciente não retornou para a realização da prótese definitiva, alegando que a prótese estava em função e estava satisfeita. Mesmo a paciente sendo fumante a cicatrização mostrou-se excelente após sete dias e a paciente não se queixou de dor pós-operatória.

\section{CONCLUSÃO}

Pode se concluir que a prótese total imediata satisfaz as expectativas da paciente, estabelecendo assim de forma rápida a função mastigatória, estética e fonética. 


\section{REFERÊNCIAS}

1. Patil MS, Patil SB. Geriatric patient - psychological and emotional considerations during dental treatment. Gerodontology. 2009;26(1):72-7.

2. Dhariwal NS, Gokhale NS, Patel P, Hugar SM. Natural tooth as an interim prosthesis. J Nat Sci Biol Med. 2016;7(2):189-93.

3. The glossary of prosthodontic terms. J Prosthet Dent. 2005;94(1):10-92.

4. Torcato LB, Pellizzer EP, Goiato MC, Falcón-Antenucci RM. Prótese total imediata: Relato de caso clínico. Rev Odontol Araçatuba. 2012;33(2):66-9.

5. Todescan R, Silva EEB, Silva OJ. Atlas de prótese parcial removível. São Paulo: Ed. Santos; 2003.

6. Fadoni A, Bomenti PR, Tanji M, Hernandes NG, Marchese MP. Prótese parcial removível (PPR) imediata. Rev Fac Odontol Lins. 2014;24(2).

7. Strini PJSA, Machado NAG, Strini PJSA, Gavião MBD, Neto AJF. Avaliação da performance mastigatória em pacientes com dentes naturais e após a reabilitação com próteses removíveis totais imediatas superior, inferior e bimaxilares - relato de casos clínicos. RFOUPF. 2011;16(2):200-5.

8. Boretti G, Bickel M, Geering AH. A review of mastication hability and efficiency. J Prosthet Dent 1995;74(4):400-5. 